\title{
PERAN TAUFIQ ISMAIL DALAM PERKEMBANGAN SASTRA DI INDONESIA
}

\author{
Nori Anggraini \\ Universitas Muhammadiyah Tangerang \\ Nory_agg@yahoo.com
}

\begin{abstract}
ABSTRAK
Salah satu sastrawan terkenal dalam perkembangan sastra Indonesia pada abad ke-20 sampai sekarang ini adalah Taufiq Ismail. Dia adalah sastrawan dalam bidang puisi Indonesia modern. Dia telah berkaya selama hampir 70 tahun dalam bidang puisi di Indonesia dan telah menghasilkan ribuan karya sastra dalam bentuk puisi. Selain sebagai sastrawan, Taufiq Ismail aktif sebagai pemerhati pengajaran sastra dan minat baca masyarakat Indonesia. Tujuan dari artikel ini adalah menganalisis peran Taufiq Ismail dalam perkembangan sastra di Indonesia terkait dengan kontribusinya dalam pengajaran sastra, baik di sekolah maupun di masyarakat. Dia adalah salah satu sastrawan Indonesia yang aktif sebagai peneliti pengajaran sastra dan minat baca masyarakat Indonesia.
\end{abstract}

Keyword: Taufiq Ismail, perkembangan sastra, pengajaran sastra

\section{A. PENDAHULUAN}

Pengajaran sastra merupakan bagian dari penyelenggaraan pendidikan nasional, yakni mewujudkan suasana dan proses pengajaran agar peserta didik secara aktif mengembangkan potensi diri untuk memiliki kekuatan spiritual, keagamaan, pengendalian, kepribadian, kecerdasan, akhlak mulia, serta keterampilan yang diperlukan oleh pribadi, masyarakat, bangsa, dan negara. Pengajaran sastra di sekolah bertujuan:1) menggunakan bahasa Indonesia untuk meningkatkan kemampuan intelektual, serta kematangan emosional dan sosial, 2) menikmati dan memanfaatkan karya sastra untuk memperluas wawasan, memperluas budi pekerti serta meningkatkan pengetahuan dan kemampuan berbahasa, 3) menghargai dan bangga terhadap sastra Indonesia sebagai khazanah budaya dan intelektual manusia Indonesia (Emizir \& Rohman, 2015). Peran karya sastra, seni, dan budaya sebagai initi dari pendidikan karakter, juga berfungsi sebagai penanam rasa kebangsaan, kebanggaan, kepahlawanan, dan kesetiaan terhadap tanah air ( Ratna, 2014).

Pengarang mempunyai peran penting dalam pendidikan sastra. Pengarang adalah sosok figur dengan kemampuan kemampuan tertentu baik emosi maupun intelektual, baik etis 
Lingua Rima: Jurnal Pendidikan Program Studi Bahasa dan Sastra Indonesia

Vol. 8 No. 1 Januari 2019

maupun estetis, termasuk psikologis sehingga karya-karyanya berhasil membawa pesan kemanusiaan. Selain itu, pengarang bisa memberikan kontribusi dengan aktif memberikan motivasi ke sekolah-sekolah untuk membangkitkan minat apresiasi dan minat membaca, dan menulis karya sastra. Hal ini merupakan sinergi yang harus dilakukan pengarang dengan dunia pendidikan (Wibowo, 2013).

Taufiq Ismail mempunyai kepedulian terhadap minat baca dan menulis bangsa Indonesia. Bersama redaksi Horison Taufiq Ismail memetakan persoalan sastra di Indonesia menjadi 14 persoalan kemudian berkembang menjadi 35 persoalan, diantaranya gejala 1) rabun membaca dan pincang mengarang; 2) bangsa Indonesia malah sudah buta membaca dan lumpuh mengarang; 3) merosotnya moralitas anak bangsa Indonesia (Ismail, 2003). Hal ini disimpulkan setelah dilakukan pemetaan lebih lanjut tentang gejala merosotnya wajib baca buku sastra, bimbingan mengarang dan pengajaran di sekolah.

\section{B. BIOGRAFI SINGKAT}

Taufiq Ismail lahir di Bukittinggi, Sumatera Barat 25 Juni 1935. Ia tumbuh dalam keluarga guru dan wartawan yang suka membaca. Ia telah bercita-cita menjadi sastrawan sejak masih SMA. Masa kanak-kanak sebelum sekolah dilalui di Pekalongan. Ia pertama masuk sekolah rakyat di Solo. Selanjutnya, ia berpindah ke Semarang, Salatiga, dan menamatkan sekolah rakyat di Yogya. Taufiq Ismail menyelesaikan SMP di Bukittinggi, setelah menyelesaikan SMA di Bogor dia kembali ke Pekalongan. Pada tahun 1956-1957 Taufiq meraih beasiswa American Field Service Interntional School untuk mengikuti Whitefish Bay High School di Milwaukee, Wisconsin, Amerika Serikat sebagai angkatan pertama dari Indonesia. Taufiq Ismail melanjutkan pendidikan di Fakultas Kedokteran Hewan dan Peternakan, Universitas Indonesia (sekarang IPB), dan tamat pada tahun 1963. Pada tahun 1971-1972 dan 1991-1992 ia mengikuti International Writing Program, University of Iowa, Iowa City, Amerika Serikat. Ia juga belajar pada Faculty of Languange and Literature, American University in Cairo, Mesir, pada tahun 1993. Karena pecah Perang Teluk, Taufiq Ismail pulang ke Indonesia sebelum selesai studi bahasanya (Sayuti, 2005).

Taufiq Ismail juga mempunyai prestasi di dunia internasional. Dia pernah diundang Dewan Bahasa dan Pustaka, Kuala Lumpur, Malaysia menjadi pembicara dan pegarang tamu. Ia juga sering mewakili Indonesia dalam festival sastra di 24 kota di Asia, Amerika, Australia, Eropa, dan Afrika sejak 1970. Puisinya telah diterjemahkan ke dalam bahasa Jawa, Sunda, Bali, Inggris, Prancis, Jerman, Rusia, dan Cina.Taufiq Ismail juga sering didaulat membacakan puisi-puisinya di berbagai ajang nasional maupun internasional. Di bidang 
Lingua Rima: Jurnal Pendidikan Program Studi Bahasa dan Sastra Indonesia

Vol. 8 No. 1 Januari 2019

musik, Taufiq Ismail juga mahir menciptakan lagu. Ia bersama Bimbo, Chrisye, Ian Antono, dan Ucok Harahap menjalin kerjasama di bidang musik tahun 1974. Dalam setiap peristiwa yang bersejarah di Indonesia Taufiq selalu tampil dengan membacakan puisi-puisinya, seperti jatuhnya Rezim Soeharto, peristiwa Trisakti, dan peristiwa Pengeboman Bali.

Taufiq merupakan salah seorang pendiri Dewan Kesenian Jakarta (DKJ), Taman Ismail Marzuki (TIM), dan Lembaga Pendidikan Kesenian Jakarta (LPKJ) (1968). Di ketiga lembaga itu Taufiq Ismail mendapat berbagai tugas, yaitu Sekretaris Pelaksana DKJ, Pj. Direktur TIM, dan Rektor LPKJ (1968-1978). Setelah berhenti dari tugas itu, Taufiq bekerja di perusahaan swasta, sebagai Manajer Hubungan Luar PT Unilever Indonesia (1978-1990) (Sayuti, 2005).

\section{Peran dalam perkembangan sastra Indonesia}

Sejarah sastra Indonesia mencatat Taufiq Ismail sebagai tokoh sastra angkatan `66 yang memiliki pengaruh cukup populer di tengah masyarakat Indonesia. Popularitas ini dicapai Taufiq melalui karya puisi yang dipublikasikan melalui berbagai media massa, baik media cetak dan elektronik, seperti majalah, koran, radio, dan televisi. Selain itu, Taufiq Ismail aktif membacakan puisi di berbagai acara, baik di dalam negeri maupun di luar negeri (Yudiono, 2010).

Taufiq Ismail mempunyai ayah seorang wartawan dan sering memuat tulisan di media massa. Begitu pula ibunya sering memuat pantun di media massa. Hal inilah yang memotivasi Taufiq Ismail untuk menulis dan berkarya agar namanya bisa tercantum di media massa seperti orang tuanya. Keinginan itu dia wujudkan melalui penerbitan puisi pertama yang dibuat Taufiq Ismail berbentuk gurindam empat baris. Pada masa itu Taufiq Ismail masih duduk di bangku kelas 2 Sekolah Dasar. Puisi tersebut kemudian dimuat di harian Sinar Baru di Ruang Anak-anak (Ismail, 2010).

Bacaan yang disukai Taufiq Ismail semasa duduk di Sekolah Menengah Atas adalah majalah Mimbar Indonesia dan Kisah (yang pada waktu itu dipimpin oleh H.B. Jassin). Taufiq Ismail dan kawan-kawannya berlomba-lomba mengirimkan karangan ke majalah tersebut. Hasilnya, karangan ia dan kawannya berhasil dimuat dalam majalah Kisah, diantaranya adalah Muhsin Dajaludin Zuhdy (sajak), Hadi Utomo (Cerpen), Sukamto A.G. (sajak), S.N. Ratmana (cerpen), dan karya Taufiq sendiri adalah berupa sajak. Pada masa Ia masih menjadi mahasiswa adalah masa ia menulis lebih produktif menghasilkan banyak karya sembari aktif dalam berbagai demonstrasi pada tahun 1966, seperti Tirani, Birpen KAMI Pusat, 1966, Benteng, Litera, 1966 (Sayuti, 2005). 
Lingua Rima: Jurnal Pendidikan Program Studi Bahasa dan Sastra Indonesia Vol. 8 No. 1 Januari 2019

Karya, karya lainnya, yaitu Puisi-Puisi Sepi, 1971, Kota, Pelabuhan, Ladang, Angin, dan Langit, 1971, Buku Tати Musium Perjuangan, Dewan Kesenian Jakarta (buklet baca puisi), 1972, Sajak Ladang Jagung, Pustaka Jaya, 1974, Kenalkan, Saya Hewan (sajak anakanak), Aries Lama, 1976, Puisi-Puisi Langit, Yayasan Ananda (buklet baca puisi), 1990, Tirani dan Benteng, Yayasan Ananda (cetak ulang gabungan), 1993, Malu (Aku) Jadi Orang Indonesia, Yayasan Ananda, 1998., Dari Fansuru ke Handayani (editor bersama Hamid Jabbar, Herry Dim, Agus R. Sarjono, Joni Ariadinata, Jamal D. Rahman, Cecep Syamsul Hari, dan Moh. Wan Anwar, antologi sastra Indonesia dalam program SBSB 2000-2001), Horison-Kakilangit-Ford Foundation, 2001, Horizon Sastra Indonesia, empat jilid meliputi Kitab Puisi, Kitab Cerita Pendek, Kitab Nukilan Novel, dan Kitab Drama (editor bersama Hamid Jabbar, Agus R. Sarjono , Joni Ariadinata, Herry Dim, Jamal D. Rahman, Cecep Syamsul Hari, dan Moh. Wan Anwar, antologi sastra Indonesia dalam program SBSB 20002001) Horison-Kakilangit-Ford Foundation, 2002 (Sayuti, 2005).

Taufiq Ismail merupakan salah satu penyair yang sering menyuarakan kritik melalui puisi terhadap ketimpangan dalam politik, sosial, dan ekonomi masyarakat Indonesia. Puisi adalah sarana untuk menyampaikan kritik tajam ketika budaya akal sehat dikebiri, ketika korupsi menjadi budaya, ketika kbhinekaan dan pluralitas tidak berdaya, maka daya kreatif diwujudkan Taufiq Ismail lewat karya-karyanya. Puisi Tirani dan Benteng merupakan karya yang sarat dengan gugatan dan sekaligus menyodorkan alternatif bersifat kritis, konseptualis, negatif dan terapis. Puisi-puisi dalam Tirani dan Benteng menggarap kecemasan, kesangsian, harapan, dan angan-angan (Ismail,2012). Dalam puisinya terdapat konsep penyadaran dan pencerahan yang tersembunyi di balik puisi-puisinya. Alat kohesi yang dominan dalam puisipuisi Taufiq Ismail adalah relasi konjungtif, pengulangan, dan keantoniman. Penggunaan alatalat kohesi ini bagaimanapun sangat membantu pembaca dalam usaha memahami makna puisi. Alat-alat kohesi ini dapat digunakan sebagai penanda yang dapat ditelusuri implikasi maknanya berdasarkan konteks bahasa yang disusun oleh penutur (Basori, 2017). Selain itu, puisi-puisi Taufiq Ismail dalam Tirani dan Benteng merupakan karya yang timbul atas peristiwa-peristiwa sejarah pada tahun 1966 (Rosidi,2000).

Karya-karya yang dihasilkan Taufiq Ismail tidak hanya berbentuk prosais, tetapi juga berbentuk liris mengekpresikan problematika kehidupan manusia. Tema-tema yang dihasilkan Taufiq Ismail dalam puisinya beragama, yaitu tentang masalah krinduan, percintaan, moral, sosial, politik, budaya, dan agama. Hal itu, menjadikan puisi-puisi Taufiq menjadi kaya akan tema-tema dari seluruh aspek kehidupan. Buku kumpulan puisi Malu (Aku) Jadi Orang Indonesia (MAJOI) Karya Taufiq Ismail, merupakan kumpulan puisi yang 
Lingua Rima: Jurnal Pendidikan Program Studi Bahasa dan Sastra Indonesia

Vol. 8 No. 1 Januari 2019

sarat dengan kritik sosial dalam masalah kehidupan rakyat Indonesia. Nilai-nilai kehidupan sosial yang terdapat dalam buku kumpulan puisi MAJOI tersebut perlu dipelajari oleh siswa dan mahasiswa agar mereka peka dengan permasalahan sosial (Idal, dkk., 2012)

Dalam kariernya sebagai penyair, Taufiq Ismail memperoleh sejumlah penghargaan dari pemerintah dan lembaga-lembaga seni budaya tingkat regional maupun internasional, yaitu: Anugerah Sei dari Pemerintah RI (1970), Cultural Visit Award dari Pemerintah Australia (1977), South East Asia Write Award (SEA Write Award) dari kerajaan Thailand (1994), Penulisan Karya Sastra Terbaik dari Pusat Bahasa Departermen Pendidikan dan Kebudayaan (1994), Sastrawan Nusantara dari Negeri Johor, Malaysia (1999), Doctor Honoris Causa dari Universitas Negeri Yogyakarta (2003) (Akademi Jakarta, 2010).

\section{Peran dalam Pengajaran sastra di sekolah}

Taufiq Ismail adalah pemerhati pengajaran sastra lebih dari 30 tahun. Hal ini menjadi bahan renungan baginya berkaitan dengan keterasingan sastra di sekolah. Penempatan sastra Indonesia yang dilihatnya hanya di trotoar peradaban bangsa, dan masalah petikan karya sastra yang tidak berada di dalam hati dan tidak terucapkan dalam pidato para pemuka Negara, serta serta minimnya jumlah doktor sastra. Berangkat dari hal tersebut, kemudian Taufiq Ismail membuat identifikasi gejala dan kemungkinan penyebabnya: (1) merosotnya minat masyarakat dalam membaca karya sastra; (2) rendahnya tiras buku sastra; (3) merosotnya mutu karya sastra; (4) sepinya ulasan dan kritik sastra; (5) kurang menaiknya jumlah pengulas dan kritukus sastra; (6) seretnya pertambahan S-3 ilmu sastra dibandingkan dengan S-3 ilmu eksakta/sains ilmu ekonomi/sosial; (7) hanya terdapat satu-satunya majalah bulanan sastra; (8) masih adanya pelarangan karya sastra; (9)lambatnya proses desentralisasi kegiatan sastra; (10) sangat kurangnya diadakan sayembara-sayembara sastra; (11) kurangnya penghargaan pada karya sasta dan sastrawannya; (12) kurang dikenalnya sastra Indonesia di luar Negeri melalui terjemahan bahasa asing; (13) tidak adanya acara sastra dan pembicaraan buku sastra di televisi; (14) merosotnya baca buku sastra dan pelajaran mengarang di sekolah (Sardjono dkk., 2006).

Berdasarkan hal tersebut, maka bersama beberapa sastrawan lainnya, Taufiq Ismail membuat beberapa kegiatan meliputi:

\section{Sisipan Kakilangit}

Sisipan Kakilangit dimulai sejak November 1996 dalam majalah sastra Horison dibuka khusus bagi siswa Sekolah Menengah Umum, Madrasah Aliyah, Pesantren dan Sekolah Menengah Kejuruan. Sisipan Kakilagit ini digunakan untuk memuat hasil 
kreativitas siswa SLTP kelas 3. Sisipan ini sangat membantu guru mengajarkan sastra di kelas. Sampai dengan Desember 2002, 71 sastrawan telah dibicarakan di Kakilangit. Horison / Kakilangit (tiras 12.000) setiap bulan sebanyak 9.000 eksemplar dikirim ke 4.500 SMU dan SMK Negeri, dilanggankan Depdiknas.

\section{Pelatihan MMAS}

Taufiq Ismail berperan dalam pelatihan Membaca, Menulis, dan Apresiasi Sastra (MMAS) untuk guru-guru Bahasa dan Sastra sejak Februari 1999 sampai dengan Oktober 2002. Pelatihan ini berlangsung sebanyak 30 angkatan, termasuk MMAS Lanjutan dengan jumalah keseluruhan peserta kurang lebih 1.500 guru, dari seluruh provinsi Indonesia. Majalah Horison berperan dalam hal ide dan materi,dukungan biaya dari Depdiknas.

\section{Sastrawan Bicara, Siswa Bertanya (SBSB)}

Kegiaatan ini berlangsung sejak tahun 2000 mendatangkan sastrawan ke sekolah membacakan puisi, cerpen, fragmen novel/drama karya mereka. Selain itu, diadakan dialog dengan siswa dan guru. Acara ini digelar di 213 SMA, 164 kota didukung oleh 113 sastrawan dan 11 aktor/aktris.

\section{Lomba Menulis Cerita Pendek (LMCP)}

Kemudian pada tahun 2002, sayembara ditambah dengan lomba menulis cerita pendek (LMCP), mengusung aktual di dunia pendidikan yang dewasa ini, yaitu pencegahan tauran dan pemberantasan salah guna narkoba di lingkungan siswa. Lomba ini diperuntukkan bagi guru Bahasa dan Sastra Indonesia SMA dan sederajat.

\section{Lomba Mengulas Karya Sastra (LMKS)}

Di tahun 2002 lomba diadakannya Lomba Mengulas Karya Sastra (LMKS) diselenggrakan pada bulan Juli hingga Oktober. Peserta harus membahas satu dari pilihan 50 novel, drama, cerpen, dan puisi. Lomba diikuti 396 peserta dari seluruh Indonesia.

\section{Pendirian Sanggar Sastra Siswa Indonesia (SSSI)}

Sanggar Sastra Siswa Indonesia(SSSI) dididrikan untuk untuk meningkatkan kebiasaan membaca, kemampuan menulis dan apresiasi sastra. Karena banyaknya peminat dan peserta sanggar maka pada tahun 2003 nama sanggar tersebut berubah menjadi Sanggar Sastra Remaja Indonesia (SSRI). Kegiatan di dalam sanggar itu dimaksudkan. Taufiq merealisasikan gagasan ini pada tahun 2002 dan dilaksanakan di 12 kota. Dimulai di Tabanan, Sumenep, Bandar Lampung, Palembang, Padang, 
Serang, Bandung, Tasik Malaya, Cirebon, Gresik, dan Yogyakarta. Harapannya, para pengasuh SSRI ini alumni MMAS yang sastrawan yang memegang gemar membimbing siswa. Dengan cara demikian, tujuan sanggar juga akan tercapai. Untuk kegiatan awal, 60 buku sastra telah disediakan. Aktivitas sanggar ini juga disponsori oleh The Ford Foundation.

\section{Sastrawan Bicara, Mahasiswa Membaca (SBMM)}

Sastrawan didatang ke 9 kampus eks IKIP pada tahun 2000-2001. Pada kegiatan ini 18 sastrawan membacakan karyanya, kemudian berdialog dengan mahasiswa yang ditugaskan membaca karya sastrawan itu sebelumnya.

\section{Penerbitan buku Dari Fansuri ke Handayani (DFH), Horison Sastra Indonesia (HSI), dan Kakilangit Sastra Pelajar (KSP)}

Anatologi DFH memuat karya 147 sastrawan. Antologi HSI terdiri dari 4 jilid. KSI adalah kumpulan karya siswa memuat 186 karya (Ismail, 2003).

\section{E. Peran dalam masyarakat}

Di bidang organisasi dan kemasyarakatan, Taufiq Ismail sangat aktif dari berbagai kegiatan. Ia pernah menjadi Pengurus Perpustakaan Sekaligus Sekretaris PIII Cabang \& Daerah Pekalongan (1954-956). Taufiq Ismail dipercayai sebagai ketua Senat Fakultas Kedokteran Hewan \& Perternakan UI Bogor (1961-1962) dan Wakil Ketua Dewan Mahasiswa UI Jakarta (1962-1963). Ia mendirikan Teater Muslim Bogor dan sekaligus menjadi sutradaranya (1964) (Sayuti, 2005).

Taufiq Ismail juga tercatat sebagai salah satu pendiri majalah Horison, yang merupakan satu-satunya majalah sastra di Indonesia yang bertahan sampai saat ini. Majalah ini didirikannya bersama Mochtar Lubis, P.K. Ojong, Zaini, Arief Budiman pada tahun 1966 (Ismail dalam Horison, 2016). Jatuh bangun dalam memperjuangkan eksistensi majalah sastra Horison bersama istrinya selama lebih kurang 50 tahun agar tetap menjadi wadah kreativitas sastrawan dan perkembangan sastra Indonesia. Sempat berhenti terbit versi cetak dan beralih menjadi majalah online pada tahun 2015, namun karena sekarang banyaknya permintaan untuk versi dicetak, maka majalah Horison kembali terbit dengan edisi 3 bulan sekali (Ismail, 2018).

Selain itu, peran Taufiq Ismail dalam perkembangan sastra di masyarakat adalah berupa pendirian "Rumah Puisi" di Aia Angek Sumatera Barat, yang merupakan tanah kelahirannya. 
Rumah Puisi ini didirikan pada tahun 2008 dalam bentuk perpustakaan dan tempat siswa melakukan apreasi sastra. "Rumah Puisi" ini merupakan swadaya pribadi Taufiq Ismail dan istrinya. Selain memuat buku-buku koleksi pribadi Taufiq Ismail, tempat ini juga merupakan sanggar pelatihan siswa dalam bidang sastra. Pelatihan dilakukan setiap hari minggu secara gratis kepada siswa di sekitar "Rumah Puisi".

Pada tahun 1974, ia terpilih sebagai anggota Dewan Penyantun, Board of Trustess AFS International, New York, bertugas sampai dengan 1976. Sejak tahun 1985 sampai kini (2018) menjadi Ketua Badan Pembina Yayasan Bina Antarbudaya, yang bekerja sama dengan badan beasiswa American Field Service, Amerika Serikat, yang menyelenggarakan pertukaran pelajar. Ketua Lembaga Seni Budaya Muhammadiyah (1998-1999). Sementara itu, sejak tahun 1970, Taufiq Ismail telah melakukan perjalanan budaya ke berbagai negara, baik secara organisasi maupun mewakili Indonesia, untuk baca puisi dan festival sastra di 24 kota Asia, Amerika Serikat, Australia, Eropa dan Afrika (Sayuti, 2005).

Selain itu,Taufiq Ismail melakukan peran lain dalam bidang sosial budaya, melalui berbagai aktivitas yang mendorong dan mendukung terbentuknya generasi muda bangsa yang lebih baik. Kegiatan tersebut diwujudkan dengan keterlibatannya dalam gerakan anti-narkoba. Peranan ini dilakukan melalui kegitan-kegiatan sosial maupun melalui penciptaan karyakarya puisi yang berkaitan dengannya dan dibacakan di berbagai kota di Indonesia. Melalui gerakan anti-narkoba ini, Taufiq Ismail mendapat penghargaan dari Presiden Megawati Soekarno Putri pada tahun 2002 untuk dedikasi dan aktivis antinarkoba (Akademi Jakarta, 2010).

\section{F. Kesimpulan}

Selain karya-karyanya memuat pendidikan karakter yang memberikan pesan moral, religius, juga memuat kritik terhadap perkembangan kebijakan-kebijakan pemerintah. Terlahir sebagai saksi sejarah beberapa peristiwa penting dalam perjalanan bangsa Indonesia, menjadikan puisi Taufiq Ismail sarat dengan peristiwa sejarah, dari zaman Orde Lama, Orde Baru, Era Reformasi, sampai era pemerintahan sekarang. Puisi-puisi yang lahirkan banyak memuat kritik atas kekuasaan yang tidak berpihak kepada masyarakat.

Tidak hanya sebagai sastrawan, Taufiq Ismail merupakan salah satu sastrawan yang peduli terhadap dunia pendidikan, khususnya pendidikan sastra di sekolah. Dari tahun 1980, dia aktif melakukan kegiatan kunjungan dengan beberapa sastrawan lainnya ke sekolah di seluruh Indonesia. Kegiatan ini dilakukan atas dasar pemetaan merosotnya minat baca masyarakat Indonesia, khususnya siswa di sekolah. Hasil penelitiannya terhadap pendidikan 
Lingua Rima: Jurnal Pendidikan Program Studi Bahasa dan Sastra Indonesia

Vol. 8 No. 1 Januari 2019

sastra di Indonesia dituangkan dalam beberapa buku yang bisa dijadukan acuan terhadap masalah pengajaran sastra di sekolah.

Taufiq Ismail juga tercatat sebagai salah satu pendiri majalah Horison, yang merupakan satu-satunya majalah sastra di Indonesia yang bertahan sampai saat ini. Selain itu, peran Taufiq Ismail dalam perkembangan sastra di masyarakat adalah berupa pendirian "Rumah Puisi" di Aia Angek Sumatera Barat, yang merupakan tanah kelahirannya. Rumah Puisi ini didirikan pada tahun 2008 dalam bentuk perpustakaan dan tempat siswa melakukan apreasi sastra. "Rumah Puisi" ini merupakan swadaya pribadi Taufiq Ismail dan istrinya. Selain memuat buku-buku koleksi pribadi Taufiq Ismail, tempat ini juga merupakan sanggar pelatihan siswa dalam bidang sastra. Pelatihan dilakukan setiap hari minggu secara gratis kepada siswa di sekitar "Rumah Puisi”.

Taufiq Ismail juga berperan dalam kegiatan anti mandat. Peranan ini dilakukan melalui kegitan-kegiatan sosial maupun melalui penciptaan karya-karya puisi yang berkaitan dengannya dan dibacakan di berbagai kota di Indonesia. Melalui gerakan anti-narkoba ini, Taufiq Ismail mendapat penghargaan dari Presiden Megawati Soekarno Putri pada tahun 2003 untuk dedikasi dan aktivis antinarkoba.

Dari paparan di atas, untuk membantu mengatasi dan memberikan solusi permasalahan pengajaran sastra di Indonesia, diperlukan peran sastrawan. Peran sastrawan tidak hanya sebagai penghasil karya sastra yang bernilai pendidikan karakter, tetapi juga mempunyai peran ikut serta membantu memberikan motivasi secara langsung ke sekolah-sekolah. Hal ini bisa dilakukan dengan cara: 1) adanya program secara pertemuan berkala antara sastrawan dan sekolah dalam hal apresiasi sastra; 2). memberikan pelatihan menulis kreatif kepada guru dan siswa; 3) adanya program cipta sastra bersama antara sastrawan, guru, dan siswa; 4) program peningkatan minat baca sastra di sekolah.

\section{G. DAFTAR PUSTAKA}

Basori.2017.Kekhohesian Teks Puisi Taufiq Ismail.Vol 13. No.2. h. 157-172.

Emzir dan Saifur Rohman. 2015.Teori dan Pengajaran Sastra. Jakarta:Raja Grafindo.

Idal, Asri \& Zulfadhli. 2012. Kritik Sosial Dalam Kumpulan Puisi Malu Aku Jadi Orang Indonesia Karya Taufiq Ismail. Jurnal Pendidikan Bahasa dan Sastra Indonesia, Vol. 1 No. 1.

Ismail, Taufiq. 2003. Agar Anak Bangsa Tak Rabun Membaca Tak Pincang Mengarang. Yogyakarta: UNY.

Ismail, Taufiq.Latar Belakang Lahirnya “Horison”.Jakarta: Horison Edisi Juli 2016. 
Ismail, Taufiq. “Horison” Kertas terbit Kembali (2018) Sekali Tiga Bulan.Jakarta: Horison Edisi Januari 2018.

Ismail, Taufiq. Benteng dan Tirani. Jakarta:Horison. 2012.

Ismail, Taufiq. 2010. Merindukan Anak Bangsa yang Membaca Buku dan Berlatih Menulis:Mengejar Ketertinggalan 60 Tahun Lamanya (dalam pidato Penyerahan Penghargaan Akademi Jakarta 2010). Jakarta:Akademi Jakarta.

Ratna, Nyoman Kutha. 2014. Peranan Karya Sastra, Seni, dan Budaya dalam Pendidikan karakter. Yogyaarta:Pustaka Pelajar.

Rosidi, Ajip. 2000. Ikhtisar Sejarah Sastra Indonesia.Bandung:Putra Bardin

Sayuti, Suminto A.2005. Taufiq Ismail:Karya dan Dunianya.Jakarta:Grasindo.

Sarjono, R Agus, dkk.2006. Mengantar Sastra ke Tengah Siswa.Jakarta:Horison.

Teater Kecil TIM. Penyerahan Penghargaan Akademi Jakarta 2010. Jakarta:Cipta, 2010.

Wibowo, Agus. Pendidikan Karakter Berbasis Sastra. Yogyakarta:Pustaka Pelajar, 2013.

Yudiono. K.S. Pengantar Sejarah Sastra Indonesia.Jakarta:Gramedia. 2010. 